\title{
Surgical Removal of Chondroma of the Petrous Apex Resulting in Hearing Improvement
}

\author{
-Case Report-
}

\author{
Tetsuro SAmeshima, Rokuya TANiKawa, Toshihide SugimUra, Naoto IZUmi, \\ Toshitaka SEKI, Takahiro MAEDA, Toshiyuki TsUbOI, Masaaki HASHIMOTO, \\ Tomofumi OSAWA, Teruo KIMURA*, and Kazuki NABESHIMA**
}

\author{
Abashiri Neurosurgical Hospital, Abashiri, Hokkaido; \\ ${ }^{*}$ Dohtoh Neurosurgical Hospital, Kitami, Hokkaido; \\ **Department of Pathology, Fukuoka University Hospital, Fukuoka
}

\begin{abstract}
An 18-year-old male presented with a chondroma in the petrous apex manifesting as major complaints of headaches and sensorineural hearing disturbance on the right. Head computed tomography and magnetic resonance imaging revealed a neoplastic lesion in the right petrous apex, which had bulged to compress the internal auditory meatus. Surgical removal improved his hearing with normalization of the postoperative air conduction threshold by reduction of the pressure of the internal auditory meatus, suggesting that the function of the cochlea was retained and the tumor was compressing the cochleal nerve at the level of the internal auditory meatus. Histological examination showed the tumor consisted of hyaline cartilage tissue without cellular atypia and the diagnosis was chondroma.
\end{abstract}

Key words: chondroma, petrous apex, surgical removal, hearing improvement, differential diagnosis

\section{Introduction}

Intracranial chondromas are extremely rare, benign cartilaginous tumors that account for $0.1-0.2 \%$ of all intracranial tumors. ${ }^{3,4)}$ The majority of intracranial chondromas occur in the skull base, and most reported cases have occurred in the parasellar region or middle fossa. Only 7 cases of chondroma occurring in the petrous apex have been reported. ${ }^{2,4,6,8,10,13,14)}$ Complete surgical removal is often difficult for chondroma occurring in the skull base and in the cavernous sinus. However, partial removal to reduce pressure seems to be adequate, since chondromas rarely invade the nerves or blood vessels directly.

In the present case, surgical removal of a chondroma of the petrous apex, manifesting as hearing loss, resulted in hearing improvement through pressure reduction of the internal auditory meatus.

\section{Case Report}

An 18-year-old male was examined by a local physician for major complaints of headaches and hearing loss on the right, which had progressed for about 2 years. Head magnetic resonance (MR) imaging revealed a well-circumscribed mass in the right petrous apex, and he was

Received March 26, 2009; Accepted June 30, 2009 referred to our hospital.

Preoperative pure-tone hearing averages were impaired at $31.3 \mathrm{~dB}$ (Fig. 1). The speech reception threshold was 40 $\mathrm{dB}$ and the speech discrimination score for the right ear was $60 \%$ at $40 \mathrm{~dB}$ above threshold. Except for the sensorineural hearing disturbance on the right side, neurological examination showed no abnormalities, even in the facial or trigeminal nerves. Computed tomography (CT) revealed that the pneumatization inside the right petrous

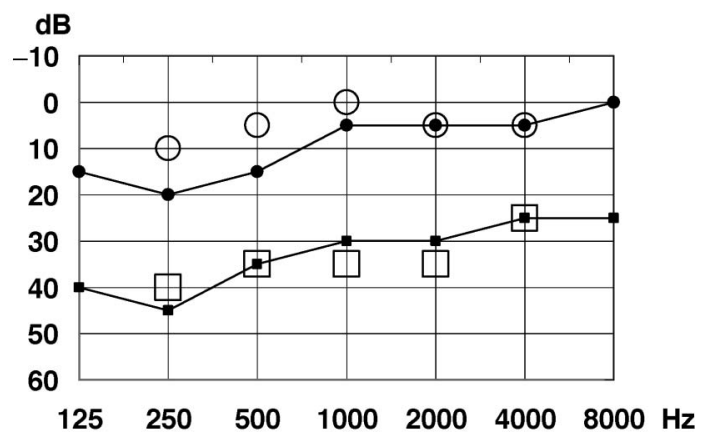

Fig. 1 Pre- and postoperative pure-tone audiograms. Closed squares: preoperative air, open squares: preoperative bone, closed circles: postoperative air, open circles: postoperative bone. 

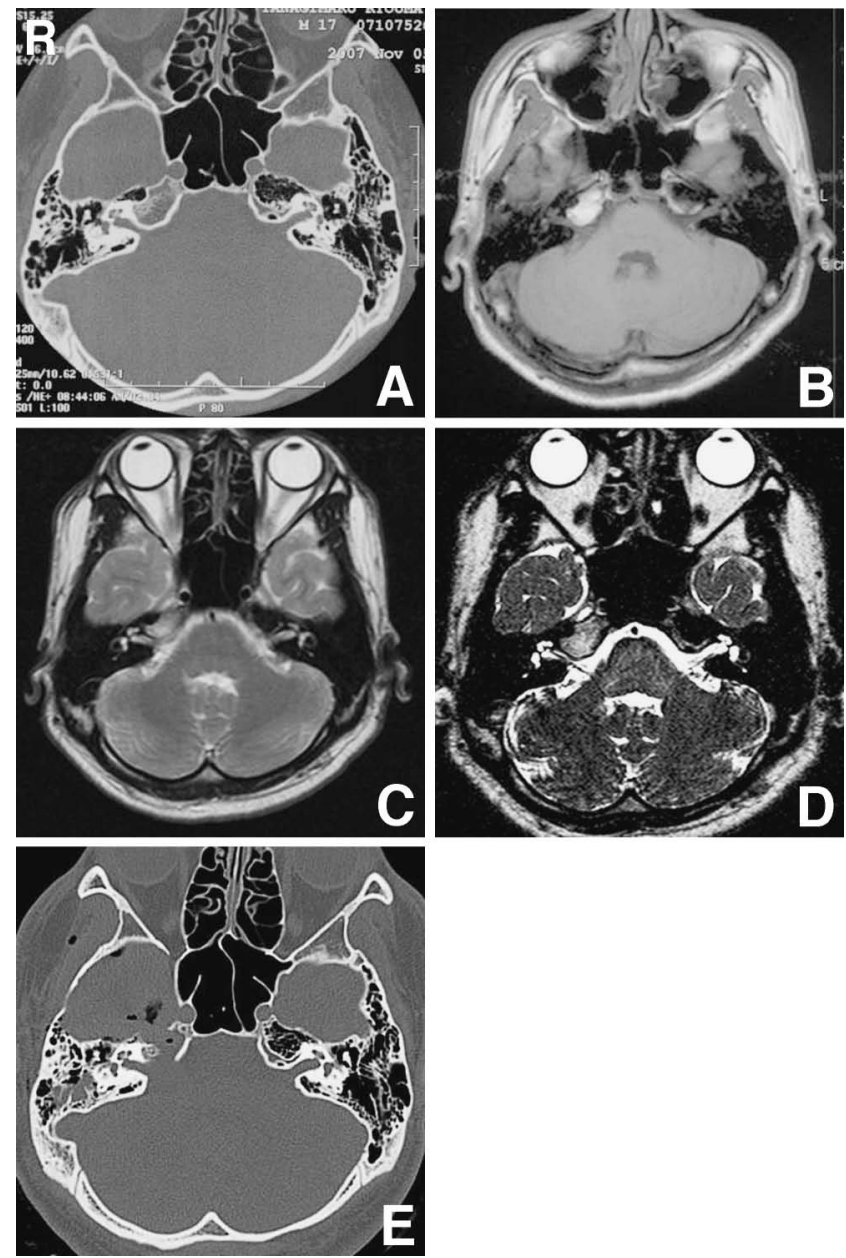

Fig. 2 A: Preoperative computed tomography scan showing that the pneumatization inside the right petrous apex had disappeared, and that the petrous apex had bulged to compress the anterior wall of the internal auditory meatus. B: $T_{1}$-weighted magnetic resonance image showing an hyperintense tumor. C: $T_{2}$-weighted magnetic resonance image showing an isointense and partial hyperintense tumor. D: Thin slice, heavy $T_{2^{-}}$ weighted magnetic resonance image showing that the tumor caused mild pressure to the internal auditory meatus. E: Postoperative computed tomography scan showing decompression of the anterior wall of the internal auditory meatus.

apex had disappeared, and that the petrous apex had bulged to compress the anterior wall of the internal auditory meatus. The bone cortex of the internal auditory meatus was intact (Fig. 2A). MR imaging showed the same region as hyperintense on $\mathrm{T}_{1}$-weighted images (Fig. 2B), and isointense to partially hyperintense on $\mathrm{T}_{2}$-weighted images (Fig. 2C). Thin slice, heavy $\mathrm{T}_{2}$-weighted $\mathrm{MR}$ images revealed that the tumor caused mild pressure to the internal auditory meatus (Fig. 2D).

Surgery was performed through a right extradural subtemporal approach. The bone cortices of the petrous apex and the internal auditory meatus appeared normal externally, but drilling revealed a multiple pseudocapsule tumor consisting of a mixture of yellow gelatinous content

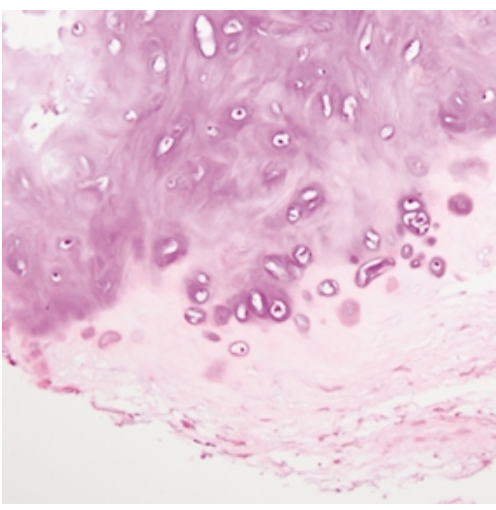

Fig. 3 Photomicrograph of the tumor showing hyaline cartilage with chondrocytes without definite atypia. Hematoxylin and eosin stain, original magnification $\times 200$.

and extremely hard, calcified material on the inside. The tumor was surgically removed with a high-speed drill, and decompression of the internal auditory meatus was performed (Fig. 2E). No abnormalities were observed in the dura mater of the internal auditory meatus or in the C5 internal carotid artery. Histological examination showed the tumor consisted of hyaline cartilage tissue without cellular atypia, and the diagnosis was chondroma (Fig. 3).

Postoperative pure-tone hearing averages improved to $7.5 \mathrm{~dB}$ at 1 month after surgery (Fig. 1). The speech reception threshold was $10 \mathrm{~dB}$, and the patient's speech discrimination score was $95 \%$ at $40 \mathrm{~dB}$ above threshold.

\section{Discussion}

Intracranial chondromas originate from embryonal cartilage cell rests in the basal synchondroses of the skull base, especially in the region surrounding the foramen lacerum. Chondrocytes are believed to form cartilage tumors because they ossify as immature cells, without passing through normal degenerative processes. ${ }^{1,8,15)}$ Intracranial chondromas can be classified into (a) sinus chondromas, (b) chondromas of the convexity and intracranial structure, and (c) basal chondromas, arising at the junction of the sphenopetrosal, petro-occipital, and spheno-occipital synchondroses. ${ }^{15)}$ However, the vast majority are basal chondromas located in the skull base, especially in the parasellar area and middle fossa. Chondromas occurring in the petrous apex are very rare, with only 7 cases reported. $2,4,6,8,10,13,14)$

Chondromas generally grow slowly, so neurological symptoms are delayed, but unilateral localized neurological symptoms caused by pressure and corresponding to the location of the tumor often appear. Chondromas in the parasellar area often cause impairment of cranial nerves II, III, IV, V, and VI, whereas chondromas of the petrous apex cause symptoms in the internal carotid artery, the mandibular division of the fifth cranial nerve (V3), the abducens nerve (VI), and the internal auditory canal structures. ${ }^{2,4,6,8,10,13,14)}$ In our case, we observed progression of hearing impairment, and preoperative imaging demon- 
strated pressure to the anterior wall of the internal auditory meatus. However, the cochlea was not damaged.

CT generally shows various densities, heterogeneous high density in the delayed phase on contrast images, and calcifications in $60-90 \%$ of cases and bone destruction in about $50 \%$ of cases. ${ }^{1,5,11)}$ MR imaging shows low to high intensity inhomogeneous signals on $\mathrm{T}_{1}$-weighted images, moderate to high intensity inhomogeneous signals on $\mathrm{T}_{2^{-}}$ weighted images, and various patterns of enhancement with contrast medium. Angiography shows poor vascularity, whereas positron emission tomography shows low uptake of fluorine-18-fluorodeoxyglucose and choline, and high uptake of technetium-99m methyl diphosphonate, which is pathognomonic of bone tumors. These findings allow the differential diagnosis of chordoma, meningioma, cavernoma, and schwannoma. ${ }^{3,5,7,16)}$ However, in cases like ours, where the chondroma is confined to the petrous apex instead of occurring in the parasellar or pericavernous areas or the middle fossa (where chondromas tend to occur), the differential diagnosis also includes cholesteatoma and chondrosarcoma. ${ }^{8,9}$

Surgical removal is the standard treatment because radiation therapy is ineffective. If complete removal is accomplished, a favorable course of the disease and long-term prognosis can be expected, ${ }^{12)}$ but if the tumor occurs in the skull base or cavernous sinus, complete removal is difficult. However, since chondromas rarely invade nerves or blood vessels directly, partial surgical removal to reduce pressure will probably be sufficiently effective. ${ }^{5,8)}$

In this case, the tumor was mainly located in the petrous apex and bulged into the internal auditory meatus. However, the tumor did not invade the cochlea, so the surgery was relatively easy. Furthermore, since the postoperative air conduction threshold was normalized by reduction of the pressure of the internal auditory meatus, the function of the cochlea was retained, with the tumor only compressing the cochleal nerve at the level of the internal auditory meatus.

\section{References}

1) Aoki A, Mori K, Tajima A, Maeda M: Sellar chondroma. Case report. Neurol Med Chir (Tokyo) 39: 870-874, 1999

2) Bouchez B, Delandsheer E, Arnott G, Clarisse J, Gozet G, Krivosic I, Courteville Delamarre V, Delandsheer JM: [Osteochondroma of the apex of the petrous bone. Clinical, neuroradiologic and functional study (evoked auditory poten- tials of the brain stem)]. Rev Otoneuroophthalmol 54: 231-239, 1982 (Fre)

3) Brownlee RD, Servick RJ, Rewcastle NB, Tranmer BI: Radiologic-pathologic correlation. Intracranial chondroma. AJNR Am J Neuroradiol 18: 889-893, 1997

4) Falconer MA, Bailey IC, Duchen LW: Surgical treatment of chordomas and chondromas of the skull base. J Neurosurg 29: 261-275, 1968

5) Higashida T, Sakata K, Kanno H, Tanabe Y, Kawasaki T, Yamamoto I: [Intracranial chondroma arising from the skull base: Two case reports featuring the image findings for differential diagnosis]. No Shinkei Geka 35: 495-501, 2007 (Jpn, with Eng abstract)

6) Komisar A, Som PM, Shugar JMA, Sacher M, Parisier SC: Benign chondroma of the petrous apex. Case report. J Comput Assist Tomogr 5: 116-118, 1981

7) Lin CY, Kao CH, Liang JA, Hsieh TC, Yen KY, Sun SS: Chordoma detected on F-18 FDG PET. Clin Nucl Med 31: 506-507, 2006

8) Mariniello G, Cappabianca P, Stella L, De Caro MLDB, Buonamassa S, de Divitiis E: Chondroma of the petrous apex. Case report. Clin Neurol Neurosurg 105: 135-139, 2003

9) Muckle RP, De la Cruz A, Lo WM: Petrous apex lesions. Am J Otol 19: 219-225, 1998

10) Tanner NSB, Shaw HJ, Clifford P: Massive chondroma of skull base. J Royal Soc Med 72: 615-617, 1979

11) Tanohata $K$, Maehara $T$, Aida $N$, Umino $S$, Matsui $K$, Mochimatsu Y, Fujitsu K: Computed tomography of intracranial chondroma with emphasis on delayed contrast enhancement. J Comput Assist Tomogr 11: 820-823, 1987

12) Terasaka S, Sawamura $Y$, Abe $H$ : Surgical removal of a cavernous sinus chondroma. Surg Neurol 48: 153-159, 1997

13) Timmis P: Chondroma of the nasopharynx. J Laryngol Otol 73: 383-387, 1959

14) Tisch M, Hehl K, Kraft K, Kunz U, Maier H: [Chondroma of the petrous bone. A contribution to differential skull base tumor diagnosis]. Laryngorhinootologie 76: 371-373, 1997 (Ger, with Eng abstract)

15) Yasargil MG: Chondromas and chordomas, in Yasargil MG (ed): Microneurosurgery, vol IVB. New York, Thieme, 1996, pp 186-187

16) Zhang H, Tian M, Oriuchi N, Higuchi $T$, Watanabe H, Aoki J, Tanada S, Endo K: 11C-choline PET for the detection of bone and soft tissue tumors in comparison with FDG PET. Nucl Med Commun 22: 273-279, 2003

Address reprint requests to: Tetsuro Sameshima, M.D., Abashiri Neurosurgical Hospital, 4-1-7 Katsura-machi, Abashiri, Hokkaido 093-0041, Japan.

e-mail: tetsurosameshima@gmail.com 